\title{
Fabrication of Paper-Templated Structures of Noble Metals
}

\author{
Dionysios C. Christodouleas, Felice C. Simeone, Alok Tayi, Sonia Targ, James C. Weaver, \\ Kaushik Jayaram, Maria Teresa Fernández-Abedul, and George M. Whitesides*
}

This manuscript describes a simple and rapid method for fabricating freestanding structures composed primarily ( $>94 \% \mathrm{w} / \mathrm{w}$, and $55-80$ at\%) of noble metals (e.g., gold, silver, platinum, etc.) and having physical morphologies that resemble paper, thread, or fabric. In this method, templates (i.e., pieces of paper, or cotton fabric) are loaded with aqueous solutions of salts of noble metals, and then the cellulosic component is burned off in a furnace held at high temperatures (i.e., from $550^{\circ} \mathrm{C}$ to $800^{\circ} \mathrm{C}$, depending on the procedure, in air). Even though the environment in a furnace is ostensibly oxidizing (e.g., hot air), the metal ions are reduced to elemental metal and form paper-templated or fabric-templated structures that have morphologies similar to that of the material from which they were derived (i.e., paper or fabric). Papertemplated structures are fibrous, permeable to gases and liquides, electrically conductive, and in some cases (e.g., paper-templated gold and papertemplated platinum structures), their surfaces are electroactive. The surface areas of paper-templated structures are more than $\mathbf{2 0}$ times higher than their projected areas. Paper-templated structures thus have properties that make them potentially useful in catalysis, sensing, and electroanalysis.

\section{Introduction}

Noble metals are used in a variety of fields, including electroanalysis ${ }^{[1]}$ and electrocatalysis. ${ }^{[2]}$ To form electrodes, bulk metals are shaped into rods, or into thin films supported on flat substrates (e.g., ceramic materials, glass):; ${ }^{[3,4]}$ thin films of noble metals may also be roughened to increase their surface areas. ${ }^{[2]}$ Alternatively, metal nanoparticles are deposited on a high-surface, inexpensive supporting electrode (e.g., carbon ${ }^{[1]}$ ). Electrodes composed of bulk noble metals do not provide high surface area per unit of weight of metal; in addition, they are not permeable to gases and liquids. Electrodes composed of

Dr. D. C. Christodouleas, Dr. F. C. Simeone, Dr. A. Tayi, S. Targ, Prof. G. M. Whitesides

Department of Chemistry and Chemical Biology Harvard University

12 Oxford Street, Cambridge, MA 02138, USA E-mail: gwhitesides@gmwgroup.harvard.edu

Dr. J. C. Weaver, Dr. K. Jayaram, Prof. G. M. Whitesides

Wyss Institute for Biologically Inspired Engineering

Harvard University

60 Oxford Street, Cambridge, MA 02138, USA

Prof. M. T. Fernández-Abedul

Departamento de Quimica Fisica y Analytica

Universidad de Oviedo

8 Julián Clavería, Oviedo, Asturias 33006, Spain

DOI: 10.1002/admt.201600229 metal nanoparticles may have high surface area per unit of weight of metal, but may (depending on the support) be impermeable to gases and liquids.

Papers and fabrics have open fibrous structures, which provide them with higher accessible surface area than flat films of similar dimensions, and are permeable to liquids and gases. If noble metals could be fabricated in structures that are morphologically similar to paper or fabric, these structures might exhibit attractive physical properties (e.g., high surface area, mechanical flexibility, permeability to gases and liquids) and might also be plausible materials for use in electroanalysis, as catalysts, electrical conductors, or magnetic collectors.

This article describes a method for fabricating free-standing materials of a number of late transition metals (i.e., noble metals); these materials have physical morphologies that resemble paper, thread, or fabric. We call the method "paper-templating," and the resulting structures "paper-templated metals." Paper-templating uses paper or fabric as a template, and solutions of metallic ions deposited on the paper or fabric as precursors to the metal. The template is first loaded with aqueous solutions of salts of noble metals and dried. The paper (or cotton fabric, in same experiments) is then burned off in a stream of air in a furnace held at temperatures between 550 and $800{ }^{\circ} \mathrm{C}$, depending on the procedure, and the resulting structure annealed for $2 \mathrm{~min}$. The method yields structures that resemble the shape and detailed morphology of the original template (Figure 1A,B); this morphology, at scales down to $2 \mu \mathrm{m}$, is remarkably similar to that of the material (e.g., paper) from which they were derived (Figure 1C-F). The structures are composed primarily $(>94 \% \mathrm{w} / \mathrm{w}$, and $55-80$ at\%) of elemental metal. Using paper-templating, we fabricated: (i) paper-templated structures of noble metals (i.e., gold, silver, platinum, rhodium, palladium, and iridium), (ii) paper-templated structures of mixtures or alloys of noble metals (i.e., gold-platinum, silverpalladium, gold-rhodium, and gold-rhodium-platinum), and (iii) paper-templated structures with different regions composed of a different noble metal (i.e., gold/silver, platinum/rhodium). These structures were electrically conductive, and permeable to gases and liquids. The surface areas of these structures were more than 20 times higher than their projected areas. The surface of paper-templated gold was electroactive, and the structure could be used as the working electrode for electroanalysis (Figure 1G,H). 

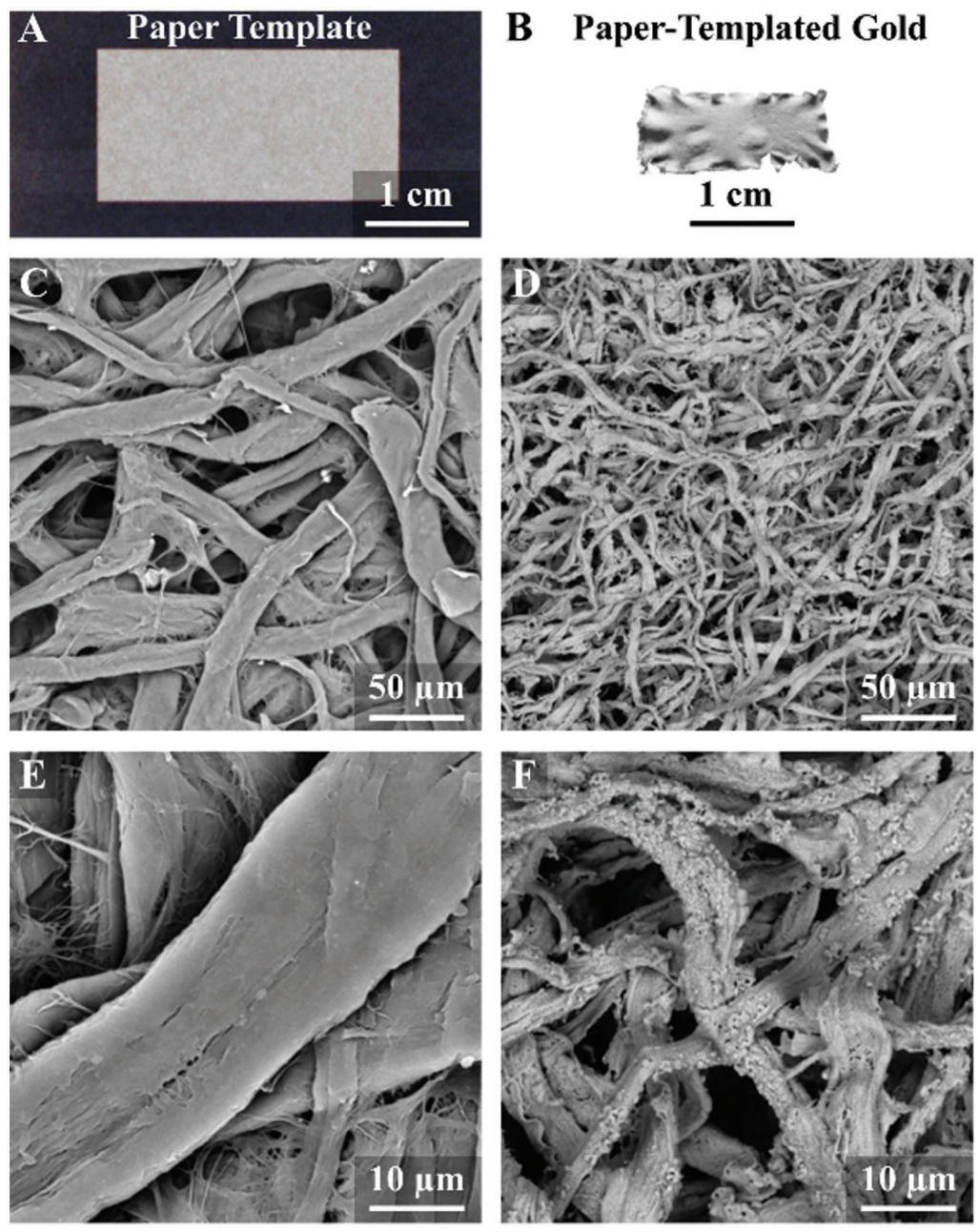
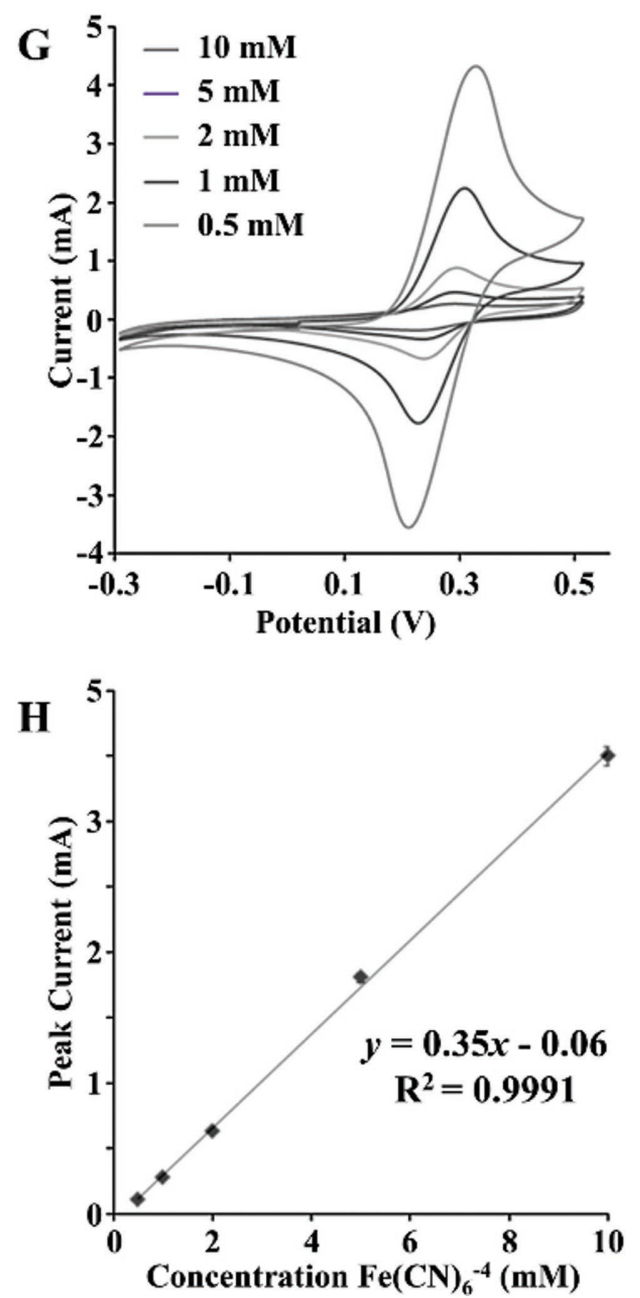

Figure 1. A,B) Photographs of the paper template (A) used to produce the paper-templated gold structure (B). C-F) SEM images of chromatography paper $(C, E)$ and paper-templated gold structure $(D, F)$ at different magnifications. $G)$ Cyclic voltammograms in solutions of Fe $(C N)_{6}{ }^{4-}(0.5-10 \times$ $10^{-3} \mathrm{M} \mathrm{Fe}(\mathrm{CN})_{6}{ }^{4-}$ in $\left.0.5 \mathrm{M} \mathrm{KCl}\right)$ recorded at $100 \mathrm{mV} \mathrm{s}^{-1}$ using a $75 \mathrm{~mm}^{2}$ paper-templated gold electrode as working electrode. A platinum mesh was used as counter electrode, and a commercial $\mathrm{Ag} / \mathrm{AgCl}$ electrode as reference electrode. $\mathrm{H}$ ) Calibration line of peak current versus concentration of $\mathrm{Fe}(\mathrm{CN})_{6}{ }^{4-}$ for the gold paper-templated electrodes.

Previous efforts to prepare porous structures of noble metals have used methodologies that were based on (i) packed colloidal spheres used as templates, ${ }^{[5-10]}$ (ii) electrospun polymeric nanostructures used as templates, ${ }^{[11,12]}$ (iii) the replacement reaction between a silver template and the salt solution of a metal (whose redox potential, $\mathrm{M}^{n+} / \mathrm{M}$, was higher than that of the $\mathrm{Ag}^{+} / \mathrm{Ag}$ couple, e.g., $\left.\mathrm{Au}\right),{ }^{[13,14]}$ and (iv) the selective dissolution of a metal from a film of metal alloy. ${ }^{[15-18]}$ Although these and similar techniques can provide films or nanostructures with well-defined pores, they require complicated experimental procedures ${ }^{[9,10]}$ and produce either nanostructures ${ }^{[11,13]}$ or very thin (on the order of a few micrometers) and fragile films. ${ }^{[9,10]}$ For example, Velev et al. used templates of colloidal spheres to prepare flakes of nanoporous gold with projected areas not bigger than $2 \mathrm{~mm}^{2} .^{[5]} \mathrm{Nam}$ and co-workers used 3D structures composed of electrospun nanofibers of catecholgrafted poly(vinyl alcohol) as templates to prepare porous nanostructures of gold, platinum, silver-gold, and silver-platinum. ${ }^{111]}$ $\mathrm{Xia}$ and co-workers synthesized aggregates of nanostructures of gold, platinum, and palladium with hollow interiors using, as templates, silver nanoparticles of various morphologies, and solutions of gold, platinum, or palladium salts as precursors to the metals; ${ }^{[13]}$ in this method, metal ions (i.e., $\mathrm{Au}^{3+}, \mathrm{Pt}^{4+}, \mathrm{Pd}^{2+}$ ) were reduced on the surface of silver nanoparticles, and an elemental metal (i.e., Au, Pt, Pd) grew into a shell-like structure, while silver nanoparticles were simultaneously oxidized to soluble silver ions. ${ }^{[13]}$ Alternatively, nanoporous thin films of gold can be prepared by dissolving silver from a film of a silver-gold alloy. ${ }^{[15]}$

Other methods used carbon-based polymeric materials, such as paper and polymeric fibers, as templates for the fabrication of (i) porous, conductive structures of carbon ${ }^{[19]}$ and (ii) porous structures of metal oxides (e.g., $\mathrm{TiO}_{2}, \mathrm{MnO}_{2}, \mathrm{Fe}_{2} \mathrm{O}_{3}$ ). ${ }^{[20-24]}$ For example, Garcia and co-workers prepared conductive carbon paper by heating paper at $1000{ }^{\circ} \mathrm{C}$ in slightly reducing conditions $\left(95 \% \mathrm{Ar}-5 \% \mathrm{H}_{2}\right) \cdot{ }^{[19]}$ Yuan et al. prepared hollow metal oxide-fibers composed of $\mathrm{TiO}_{2}$ or $\mathrm{Fe}_{2} \mathrm{O}_{3}$ by coating carbon fibers with solutions of precursors of the metal oxides, and 
then removing the carbon fibers by oxidation. ${ }^{[20]}$ Kunitake and Huang prepared paper-templated films of $\mathrm{TiO}_{2}$ by heating filter paper loaded with titanium butoxide from room temperature to $450{ }^{\circ} \mathrm{C}$, in air. ${ }^{[24]}$ They also attempted to use the same approach to prepare a paper-templated structure of silver, using solutions of $\mathrm{AgNO}_{3}$, but, instead, produced a metallic powder of silver. ${ }^{[25]}$ They were able to fabricate a free-standing structure of silver fiber only after using sodium borohydride to reduce the silver ion to silver, and then burning the paper to fuse the silver nanoparticles together. These structures had morphology similar to that of paper, but their shapes were irregular. ${ }^{[25]}$

\section{Results and Discussion}

\subsection{Fabrication of the Structures}

This work describes a method to prepare free-standing papertemplated structures composed predominantly ( $\approx 95 \%$ by mass; $55 \%-80 \%$ by elemental composition) of most of elements considered to be noble metals (i.e., gold, silver, platinum, rhodium, palladium, and iridium), but containing significant amounts of carbon and oxygen. We fabricated the structures as follows: We used templates made of chromatography paper grade A, and defined the hydrophilic region of each template by printing hydrophobic barriers composed of wax-based ink. We then added onto the hydrophilic region an aqueous salt solution of metallic ions (e.g., for the gold structure $\approx 7.5 \mathrm{mg}$-atom $\mathrm{cm}^{-2}$ for chromatography paper that was $180 \mu \mathrm{m}$ thick). The Supporting Information reports the exact concentration and volume of salt solution used for each structure. We let water evaporate from the paper template at $70{ }^{\circ} \mathrm{C}$. After the paper template dried, we cut off the hydrophobic barriers and placed it between two flat layers of stainless steel mesh. The template was then placed in a furnace preheated to high temperatures (i.e., from 550 to $800{ }^{\circ} \mathrm{C}$, depending on the procedure) in air. Inside the furnace, the template autoignited and the paper burned off within a few seconds, yielding a paper-templated metallic structure. We left this structure in the furnace for $2 \mathrm{~min}$ to anneal, and then we let it cool to room temperature. We carefully removed one layer of the stainless steel mesh and then removed the paper-templated metallic structure (Figure S1, Supporting Information).

The composition of the solution applied to the original template determined the final composition of the metallic structure. By using solutions containing a mixture of metallic ions, we prepared paper-templated structures composed of (i) gold and platinum $(\mathrm{Au}-\mathrm{Pt})$, (ii) silver and palladium $(\mathrm{Ag}-\mathrm{Pd})$, (iii) gold and rhodium (Au-Rh), and (iv) gold, rhodium, and platinum (Au-Rh-Pt) (Figure S1, Supporting Information). The detailed experimental procedure is described in the Supporting Information. We also prepared paper-templated structures where the two halves of the structure were composed of a different noble metal (i.e., gold and silver (Au/Ag), and platinum and rhodium (Pt-Rh)) (Figure 2A,B); these structures were generated by wetting the two halves of a rectangular paper template with separate solutions containing different metal ions (see the Supporting Information for the experimental procedure). Figure $2 \mathrm{C}-\mathrm{F}$ shows that each half of the structure was composed primarily of a single metal and a gradient in
A
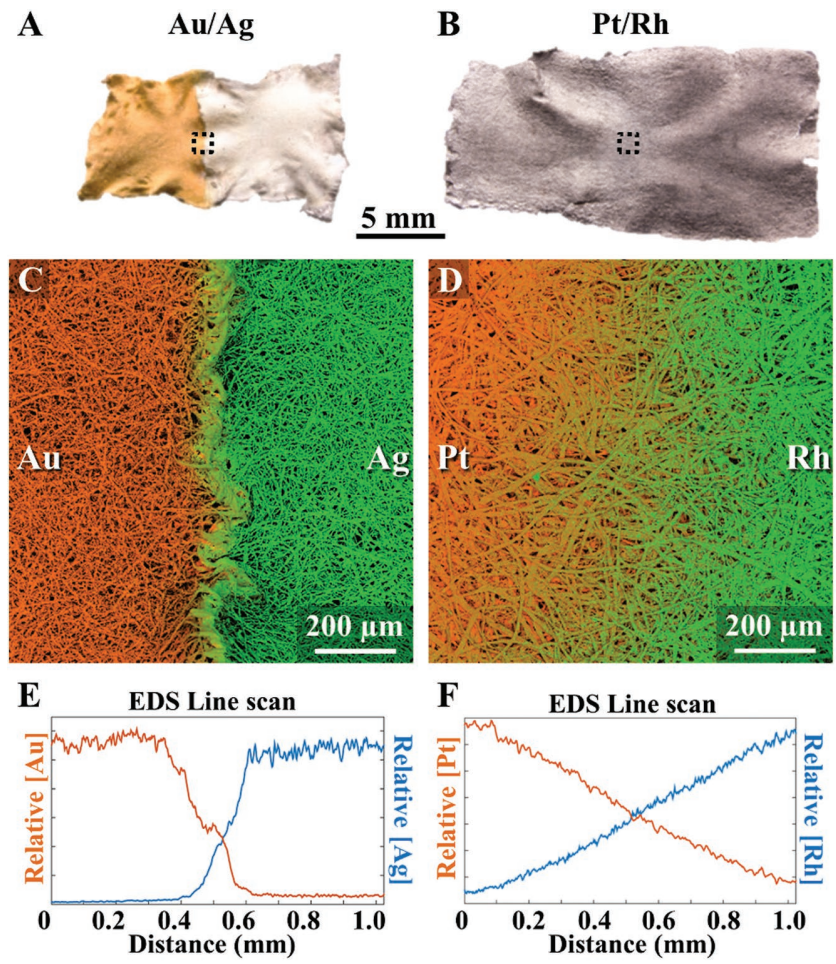

Figure 2. $A, B)$ Photographs of the paper-templated gold/silver $(A)$ and platinum/rhodium (B) structures. C,D) EDS maps of regions (indicated in the dotted squares) of the paper-templated gold/silver (C) and platinum/rhodium (D) structures. E,F) Plots indicating the relative concentration of gold and silver (E) and platinum and rhodium (F) depending on the distance from the middle of the structure; the plots were derived from the EDS maps.

composition at the interface between them. There are three plausible contributors to the relatively sharp segregation of the metals (tens to hundreds of $\mu \mathrm{m}$ ). (i) Once the two solutions of metallic ions met in the middle of the rectangular template, capillarity-driven flow of liquid through the paper stopped.[26] (ii) Diffusion of metallic ions, due to concentration gradients across the interface between the two liquids, occurred only on the scale of less than a millimeter before water evaporated completely (Figure 2E,F). (iii) The mobility of the ions was reduced, even in the presence of water, by absorption on the surface of the paper.

\subsection{Physical Properties and Morphology of Paper-Templated Structures}

Paper-templating generated structures that were free-standing and almost flat (with wrinkles mainly due to the warping of the structure that occurred during the combustion of the cellulose). The shape of the structures could be tailored by using templates of different shapes. Figure S2 (Supporting Information) shows paper-templated structures made of gold, silver, platinum, and rhodium that have triangular, square, rectangular, and circular shapes depending on the shape of the original structure.

All of the paper-templated structures were flexible with the exception of those composed of iridium and palladium, which 
were fragile and brittle. Among the samples we fabricated, the paper-templated structures of silver were the most robust; we prepared paper-templated silver structures that remained intact even when we creased or scrolled them (Figure S3, Supporting Information). We performed a bending test (see the Supporting Information for the details), and determined the rotational stiffness (i.e., ratio of the maximum torque to maximum angular deformation) and the permanent set (i.e., the angular deformation remaining in the material after the stress is released) of the native chromatography paper and that of the gold, silver, and platinum paper-templated structures. We concluded that paper-templated silver had the highest rotational stiffness $\left(33 \pm 1 \mu \mathrm{N} \mathrm{m} \mathrm{rad}{ }^{-1}\right)$ followed by paper-templated gold $(2.0 \pm$ $\left.0.6 \mu \mathrm{N} \mathrm{m} \mathrm{rad}{ }^{-1}\right)$ and paper-templated platinum $(0.8 \pm 0.1 \mu \mathrm{N}$ $\left.\mathrm{m} \operatorname{rad}^{-1}\right)$; all the structures, however, showed significantly lower rotational stiffness than the native chromatography paper (78 $\pm 1 \mu \mathrm{N} \mathrm{m} \mathrm{rad}{ }^{-1}$ ). Paper-templated platinum exhibited the highest permanent set $\left(8 \pm 2^{\circ}\right)$ followed by paper-templated gold $\left(4 \pm 1^{\circ}\right)$ and paper-templated silver $\left(2.3 \pm 0.9^{\circ}\right)$. The permanent set in the native chromatography paper was $3.0 \pm 0.4^{\circ}$.

To test whether the paper-templated structures were permeable to liquids, we placed gold or silver paper-templated structures between two sheets of paper, pressed them, and added a drop of water on top of one layer of paper. Water wicked slowly through the paper-templated structures to the bottom piece of paper.

The footprint areas of the metallic structures were smaller than those of the original templates by at least a factor of 1.5 (Figures S1 and S2, Supporting Information). The projected areas of rhodium and platinum structures were $\approx 0.6$ of the areas of the original templates. For gold structures, the projected area of the paper-templated structures was $\approx 0.3$ that of the area of the original template. The mean thickness of the structures was between 50 and $150 \mu \mathrm{m}$, depending on the metal used (Table S1, Supporting Information). The average thickness of the silver structures was $150 \pm 20 \mu \mathrm{m}(N=5)$, while the average thickness of the iridium structure was $50 \pm 4 \mu \mathrm{m}(N=5)$. The thickness of the native chromatography paper was $180 \mu \mathrm{m}$.

To the naked eye, the paper-templated structures appeared fibrous and porous. Scanning electron microscopy (SEM) confirmed that the structures were composed of metallic fibers that, remarkably, were interconnected and formed a continuous network that resembled that of the paper from which they were derived (Figure 1C-F, Figures S4 and S5, Supporting Information); the diameter of the metallic fibers ranged from 2 to $10 \mu \mathrm{m}$. The morphologies of the metallic fibers were influenced by (i) the noble metal and (ii) the amount of the metallic ion used as precursor. For example, gold and silver fibers appeared solid, while the platinum ones appeared porous (Figure 1F, Figure S4B,D, Supporting Information). Figure S6 (Supporting Information) shows that the morphology of the gold fibers was influenced by the initial amount of gold ion deposited on the template; the less gold deposited, the more porous the gold fibers. The porosity of the paper-templated structures, therefore, can be tailored by changing the quantity of metallic salt deposited on the template.

Because they were fibrous and porous, the paper-templated structures had surface areas that were higher than the projected areas. We measured the specific surface area (using a multipoint
Table 1. Specific surface area of paper-templated structures and other materials.

\begin{tabular}{lcc}
\hline Material & $\begin{array}{c}\text { Specific surface area } \\
{\left[\mathrm{m}^{2} \mathrm{~g}^{-1}\right]}\end{array}$ & $\begin{array}{c}\text { Specific surface area } \\
{\left[\mathrm{m}^{2} \text { g-atom }{ }^{-1}\right]}\end{array}$ \\
\hline Original paper template & 1.14 & - \\
Paper-templated Au & 0.24 & 47 \\
Paper-templated Ag & 0.11 & 12 \\
Paper-templated Pt & 0.75 & 146 \\
Au foil (0.025 mm) & 0.016 & 3.1 \\
Nanoporous gold & $6.4^{\mathrm{a})}$ & 1240 \\
Exfoliated graphite & $84^{\mathrm{b})}$ & 1008 \\
Mesoporous alumina & $365^{\mathrm{c})}$ & - \\
Pt NPs on mesoporous silica & $690-830^{\mathrm{d})}$ & $134300-161500$ \\
\hline
\end{tabular}

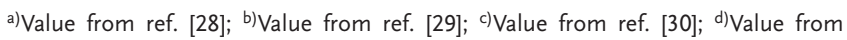
ref. [31].

Brunauer, Emmett, and Teller (BET) method; krypton was used as adsorbate gas) of the gold, silver, and platinum papertemplated structures (Table 1). For comparison, we also measured the specific surface area of the original paper used as the template and that of a $0.025 \mathrm{~mm}$ thick gold foil (Table 1). The paper-templated metallic structures had an area that was $\approx 0.2$ of the area of the paper, but $\approx 15$ times that of the thin gold metal foil, and more than 20 times that of the projected area of the structure. We mention, for comparison, that $\mathrm{Hu}$ et al. prepared nanoporous gold structures (by dissolving silver from a silver/ gold alloy) that had surface areas 9.2 times larger than that of a flat structure. ${ }^{[27]}$ Stine and co-workers measured the specific surface area of nanoporous gold structures (using the BET method), prepared by dissolving silver, copper, zinc, and nickel from a 10 carat white gold sheet, equal to $6.4 \mathrm{~m}^{2} \mathrm{~g}^{-1}$. The specific surface areas of the structures, however, were reduced to $1.79 \mathrm{~m}^{2} \mathrm{~g}^{-1}$ when they were annealed at $400{ }^{\circ} \mathrm{C}$ for $60 \mathrm{~min} .{ }^{[28]}$ Preliminary results on the paper-templated gold structures suggested that we could prepare paper-templated metallic structures of even higher surface area $\left(\approx 1 \mathrm{~m}^{2} \mathrm{~g}^{-1}\right)$ by reducing the amount of metal precursor added on the paper template, these structures were, however, fragile. Other structures (i.e., exfoliated graphite, mesoporous alumina, supported platinum nanoparticles on mesoporous silica powder) reported in the literature ${ }^{[29-31]}$ exhibited much higher surface area than paper-templated structures (Table 1), but they were not free-standing.

\subsection{Characteristics and Composition of Paper-Templated Structures}

The color of each paper-templated structure (Figures S1 and S2, Supporting Information) matched the color of the elemental metal of which it was composed. We calculated the composition of each structure using energy dispersive spectroscopy (EDS): EDS estimated the composition of the outer parts of the paper-templated structures (less than $2 \mu \mathrm{m}$ inside the body of the fiber). Table 2 shows the mass and the atomic percentages of the target noble metals in each paper-template structure. In all structures, the mass percentages of the target noble metals 
Table 2. Composition of the paper-templated structures (composed of one noble metal element).

\begin{tabular}{|c|c|c|c|c|c|c|}
\hline \multirow{2}{*}{$\begin{array}{l}\text { Paper-templated } \\
\text { structure }\end{array}$} & \multicolumn{2}{|c|}{ Noble metal } & \multicolumn{2}{|c|}{ Oxygen } & \multicolumn{2}{|c|}{ Carbon } \\
\hline & [mass \%] & [at\%] & [mass \%] & [at\%] & [mass \%] & [at\%] \\
\hline $\mathrm{Au}$ & 95 & 55 & 0.9 & 6.6 & 4.1 & 38 \\
\hline $\mathrm{Ag}$ & 95 & 69 & 2.2 & 10 & 3.2 & 21 \\
\hline $\mathrm{Pt}$ & 97 & 67 & 0.5 & 4.2 & 2.5 & 29 \\
\hline $\mathrm{Rh}$ & 96 & 78 & 2.0 & 10 & 1.7 & 12 \\
\hline $\mathrm{Pd}$ & 95 & 74 & 4.0 & 21 & 0.7 & 5.2 \\
\hline Ir & 95 & 56 & 2.9 & 18 & 2.5 & 26 \\
\hline
\end{tabular}

exceeded $94 \%$ (their atomic percentages ranged from 55\% to $80 \%$ ). Carbon and oxygen were present in all structures, but their mass percentages were below 6\% (Table 2). Depth-profile X-ray photoelectron spectroscopy (XPS) experiments verified that carbon and oxygen were present mainly on the surface of the structure (i.e., in the upper few nanometers). Specifically, we removed $10 \mathrm{~nm}$ of the surface material by sputtering argon and we measured the composition of the new surface of the metallic structures. The atomic percentages of carbon and oxygen in the structures were reduced compared to those of the initial surface of the structures (Table S2, Supporting Information). We therefore concluded that (i) the noble metals were mainly in elemental form; EDS results show that, in all cases, the atomic percentage of oxygen in the structures was less than half that of the noble metal; this ratio implies that metal oxides, although present in the surface, were not the main components of the structures; (ii) oxygen was part of metal oxides that formed at the surface of the metallic fibers probably during cooling to room temperature; for example, platinum, iridium, and rhodium form oxides when heated in presence of oxygen; ${ }^{[32]}$ and (iii) carbon is in elemental form, which, we presume, was formed during the combustion of the paper template; we infer that carbon did not result from the formation of carbides of noble metals, because they require more extreme conditions (e.g., during laser ablation or laser desorption processes) than those used here. ${ }^{[33]}$

\subsection{Electrical Properties of Paper-Templated Structures}

The paper-templated metallic structures were electrically conductive and exhibited a linear variation (Ohmic behavior) of the electrical current with the applied voltage. The apparent volume resistivities of these structures, however, were $\approx 1000$ times higher than those of sheets of pure metals (Table 3). ${ }^{[34]}$ We suggest three possible causes: (i) the resistance associated with the oxides and impurities found in the structures contributed to their resistance; (ii) the contact resistance at points where current passed from one fiber to the next was high; and (iii) the constriction resistance (i.e., the resistance associated with the flow of the current through cross-sectional areas much smaller than the average of the sample). ${ }^{[35]}$ Constriction resistance originates mainly at point contacts between fibers, and at regions of the fibers of irregular thickness; constriction resistance can dominate the resistance of an entire sample, especially when the sample is composed of a highly conductive material. ${ }^{[35]}$

\subsection{Paper-Templated Electrodes in Electrochemical Cells}

Noble metals are often used for the fabrication of electrodes for electroanalytical measurements, and for electrocatalysis. To test the performance of paper-templated gold and platinum structures (which were permeable to liquids) as electrodes in an electrochemical cell, we recorded cyclic voltammograms in $5 \times 10^{-3}$ M solutions of $\mathrm{Fe}(\mathrm{CN})_{6}{ }^{4-}$ at scan rates between 10 and $150 \mathrm{mV} \mathrm{s}^{-1}$ (Figure S7, Supporting Information). The $\mathrm{Fe}(\mathrm{CN})_{6}{ }^{4-} / \mathrm{Fe}(\mathrm{CN})_{6}{ }^{3-}$ couple is a well-characterized reversible redox system commonly used as a model system. ${ }^{[36]}$

For both paper-templated gold and platinum electrodes the $\mathrm{Fe}(\mathrm{CN})_{6}{ }^{4-} / \mathrm{Fe}(\mathrm{CN})_{6}{ }^{3-}$ couple exhibited a quasi-reversible behavior; the values of the ratio of the anodic to cathodic peak current $\left(i_{\mathrm{pa}} / i_{\mathrm{pc}}\right)$, in fact, were slightly higher than unity, and the separation of peak potentials $\left(E_{\mathrm{pa}}-E_{\mathrm{pc}}\right)$ exceeded, at all scan rates, $59 \mathrm{mV}$ (Figure S8A-D, Supporting Information), which is the separation between anodic and cathodic peak potentials expected for reversible redox process under the assumption of planar diffusion. ${ }^{[37]}$ The values of the logarithm of anodic peak current varied linearly with the logarithm of scan rate (Figure S8E,F, Supporting Information), but with a slope greater than 0.5 , which is the value predicted by the Randles-Sevcik equation assuming planar diffusion of the redox species toward, and away from, the electrode. ${ }^{[37]}$ This equation, in fact, assumes that the electrodes are flat, and that the diffusion layers of the redox reagents are semi-infinite. ${ }^{[37}$ These two conditions are not met by paper-templated electrodes because (i) paper-templated electrodes are fibrous and rough, and have pores (with pore

Table 3. Volume resistivity of each paper-templated structure and of bulk noble metals.

\begin{tabular}{lcc}
\hline $\begin{array}{l}\text { Metal of paper-templated } \\
\text { structure }\end{array}$ & $\begin{array}{c}\text { Resistivity } \\
{[\mathrm{m} \Omega \mathrm{mm}]}\end{array}$ & $\begin{array}{c}\text { Resistivity of bulk meta }{ }^{\text {a) }} \\
{[\mathrm{m} \Omega \mathrm{mm}]}\end{array}$ \\
\hline $\mathrm{Au}$ & 39 & 0.022 \\
$\mathrm{Ag}$ & 25 & 0.016 \\
$\mathrm{Pt}$ & 82 & 0.104 \\
$\mathrm{Rh}$ & 123 & 0.048 \\
$\mathrm{Pd}$ & 360 & 0.105 \\
$\mathrm{Ir}$ & 24 & 0.051 \\
$\mathrm{Au} / \mathrm{Ag}^{\mathrm{b})}$ & 21 & - \\
$\mathrm{Au} / \mathrm{Ag}^{\mathrm{c})}$ & 372 & - \\
$\mathrm{Pt} / \mathrm{Rh}$ & 724 & - \\
$\mathrm{Au}-\mathrm{Pt}$ & 136 & - \\
$\mathrm{Ag}-\mathrm{Pd}$ & 581 & - \\
$\mathrm{Au}-\mathrm{Rd}$ & 665 & - \\
$\mathrm{Au}-\mathrm{Pt}-\mathrm{Rh}$ & 39 & - \\
\hline
\end{tabular}

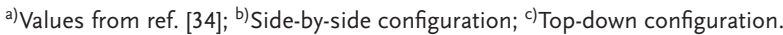


sizes ranging from several nanometers to a few micrometers), and (ii) gradients in concentrations and patterns of diffusion, occur in different regions of a paper-templated electrode at the same time due to the roughness and the porosity of the electrodes. We, therefore, conclude that (i) the paper-templated electrodes act as rough, porous, quasi-planar electrodes and (ii) the measured currents influenced both by semi-infinite diffusion to a rough planar electrode (outer surface and large pores) and through a thin stationary layer inside the small pores. ${ }^{[38]}$

From the capacitive currents recorded in the voltammograms, we estimated an electrochemically active surface area of $0.025 \mathrm{~m}^{2} \mathrm{~g}^{-1}$ for gold, and of $0.105 \mathrm{~m}^{2} \mathrm{~g}^{-1}$ for platinum, paper-templated structures (see the Supporting Information for details). The electrochemically active surface area of the paper-templated structures was $<0.14$ that of the surface area estimated by the BET method. Two plausible origins of the difference are: (i) krypton gas could reach areas of the structures (e.g., small pores) that were not accessible to solutions, and (ii) non-metallic (or non-conductive) components of the electrodes and perhaps impurities on their surfaces reduced the electrochemically active surface area.

We used paper-templated gold as the working electrode in an electrochemical cell used for electroanalysis. To calibrate the electrochemical response of the electrode, we recorded cyclic voltammograms in solutions of $\mathrm{Fe}(\mathrm{CN})_{6}{ }^{4-}$ at different concentrations (i.e., $0.5-10 \times 10^{-3} \mathrm{M}$ ) (Figure $1 \mathrm{G}$ ). Figure $1 \mathrm{H}$ shows that the average intensity of the peak currents varied linearly with the concentration of $\mathrm{Fe}(\mathrm{CN})_{6}{ }^{4-}$, and reproducibility was adequate for routine electroanalysis.

\subsection{Fabric-Templated and Sponge-Templated Structures}

To demonstrate the applicability of paper-templating to the fabrication of structures with morphology more complex than nonwoven paper, we prepared structures templated using cotton lace and woven fabric (Figure 3, Figures S9 and S10A-D, Supporting Information). Figure 3 shows that lace-templated silver structure retained the woven morphology of the lace template to a remarkable extent.

We also fabricated nonplanar, 3D metallic structures by using urethane sponges as templates. These sponge-templated silver structures retained the porosity and the general morphology of the starting sponges (Figure S10E,F, Supporting Information).

\subsection{Mechanism of the Reduction of Metal lons}

While previous studies have examined the chemical reactions that occur during the combustion of paper, ${ }^{[39]}$ the exact set of chemical reactions and intermediate products, especially during oxidation with an active flame that leads to the paper-templated structures of noble metals we have observed, is not known.

We propose two possible mechanisms for the reduction of noble metal ions deposited on the surface of the template. (i) One possibility is that they result from the reduction of metal ions to elemental metals by carbon monoxide and hydrogen formed during the combustion of paper. In the present study, we incinerated the paper templates at temperatures
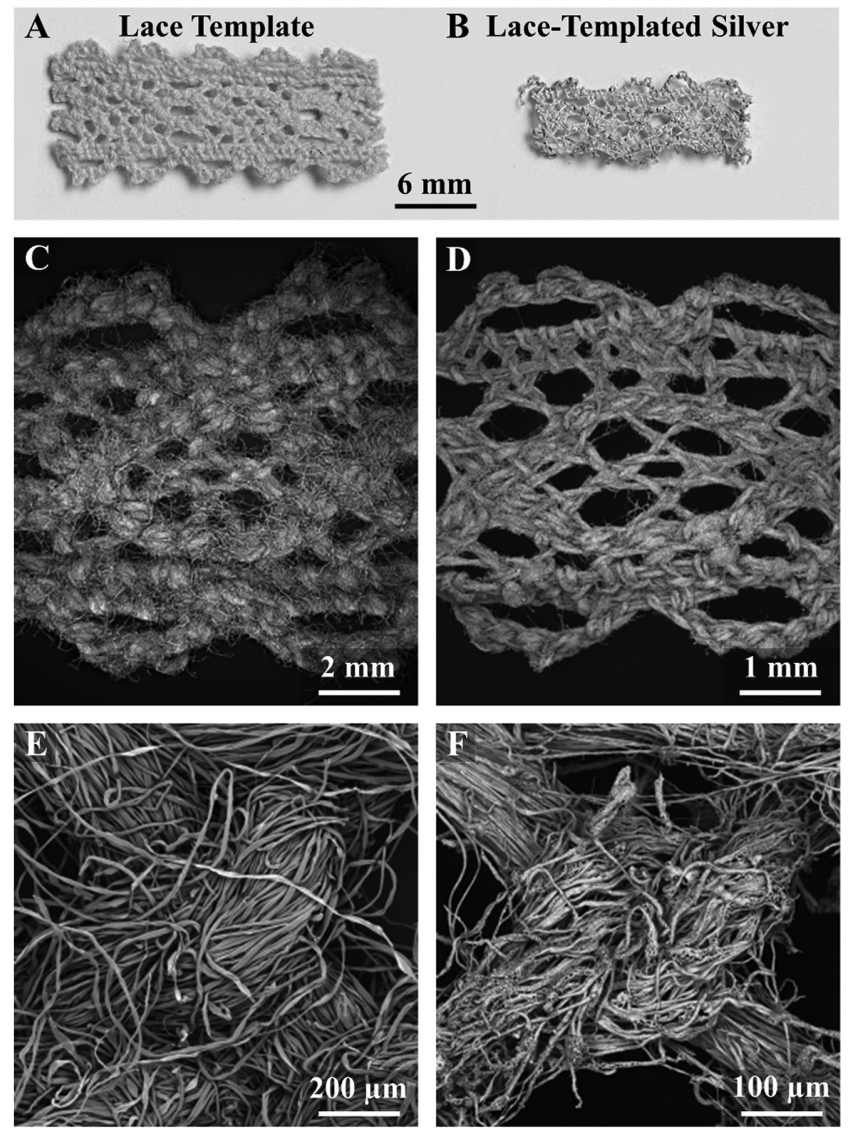

Figure 3. $A, B)$ Photographs of the lace template $(A)$ and the lace-templated silver structure (B). C-F) SEM images of the lace $(C, E)$ and the lace-templated silver structure $(D, F)$ at different magnifications.

and atmospheres similar to those used by Cullis et al. for the combustion of cellulose (at $550{ }^{\circ} \mathrm{C}$ in atmospheres containing $21 \% \mathrm{v} / \mathrm{v}$ oxygen and $79 \% \mathrm{v} / \mathrm{v}$ nitrogen); those combustion experiment yielded carbon monoxide $\left(7.3 \mathrm{mmol} \mathrm{L}^{-1}\right)$, carbon dioxide $\left(5.8 \mathrm{mmol} \mathrm{L}^{-1}\right)$, and hydrogen $\left(1.2 \mathrm{mmol} \mathrm{L}^{-1}\right) \cdot{ }^{[40]}$ At high temperatures, carbon monoxide and hydrogen are both strong reducing agents; carbon monoxide, in fact, is typically used in metallurgy for the reduction of $\mathrm{Fe}_{2} \mathrm{O}_{3}$ to elemental iron in a blast furnace. ${ }^{[41]}$ We believe that, in proximity to the burning paper, the concentration of carbon monoxide and hydrogen may be high enough to reduce metal ions to elemental noble metal; Ellingham diagrams suggest that, under specific experimental conditions (i.e., temperature, $\mathrm{pO}_{2}, \mathrm{pCO}, \mathrm{pCO}_{2}$, $\mathrm{pH}_{2}$ ), the free energy of the reaction of carbon monoxide and hydrogen with oxides of noble metals is negative and, therefore, thermodynamically favorable (Figure S11, Supporting Information). ${ }^{[42]}$ (ii) The second possibility is that metallic papertemplated structures result from the thermal decomposition of salts of noble metals to elemental metals at high temperatures. When dried on paper, salt solutions of noble metals ions crystallized as salts. Salts of noble metals, however, are unstable at high temperatures and can decompose through several routes to elemental metal. For example, $\mathrm{AgNO}_{3}$ decomposes in the temperature range of $360-515{ }^{\circ} \mathrm{C}$ to $\mathrm{Ag}, \mathrm{NO}_{2}, \mathrm{NO}$, and $\mathrm{O}_{2} \cdot{ }^{[43]}$ The combustion of paper releases heat that increases the 

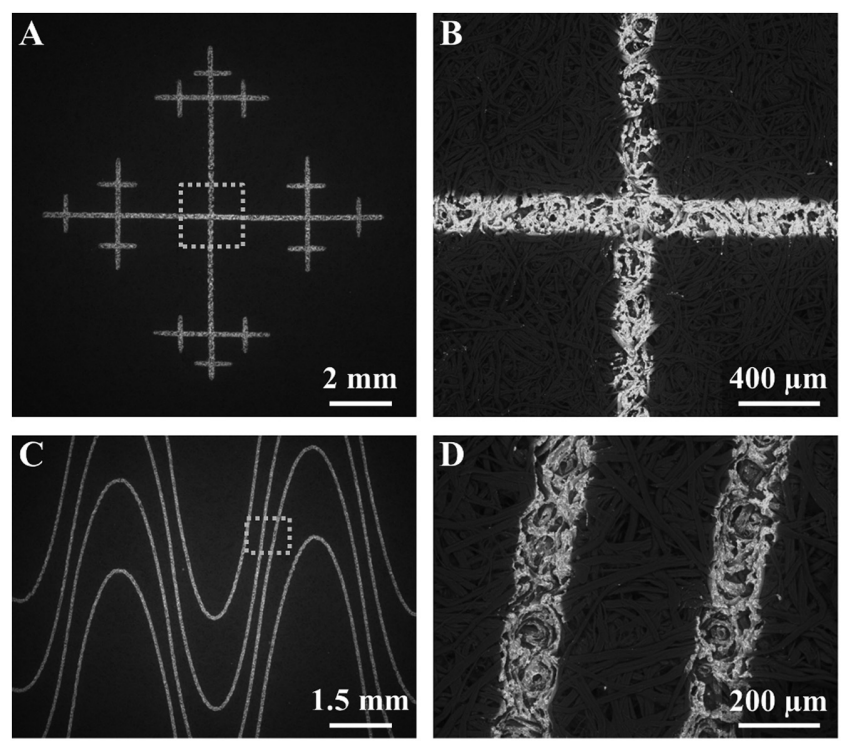

Figure 4. A,B) SEM images of two patterns of silver wires generated on, and in, a paper substrate using a laser cutter. C,D) The EDS maps indicate the location of elemental silver (light gray) and carbon (dark gray).

temperature of the template above that of the furnace; based on the color of the burning template inside the furnace (the color was red to orange), we estimated that the actual temperature of the burning template can reach $\approx 850{ }^{\circ} \mathrm{C}$. These temperatures may be high enough, in some cases, to cause the decomposition of the salts to clusters of elemental metal (e.g., to elemental silver). $\mathrm{RhCl}_{3}$, however, decomposes between 650 and $750{ }^{\circ} \mathrm{C}$ to $\mathrm{Rh}_{2} \mathrm{O}_{3}$, which, in turn, decomposes to elemental Rh only at 1040-1060 ${ }^{\circ} \mathrm{C} .{ }^{[44]} \mathrm{IrCl}_{3}$ decomposes between 500 and $680{ }^{\circ} \mathrm{C}$ to $\mathrm{IrO}_{2}$, and then to elemental Ir at $1025-1070{ }^{\circ} \mathrm{C}$. ${ }^{[4]}$

\subsection{Fabrication of Conductive Silver Lines Using a Laser Cutter}

To generate paper-templated silver wires of arbitrary shapes embedded in, and on, paper, (Figure 4) we used the laser beam found in a commercial laser cutter. The laser beam could precisely burn the template locally, and therefore induce the reduction of the silver ions to form $100 \mu \mathrm{m}$ wide lines (the Supporting Information describes the details of this procedure). Although fragile when they were creased or bent significantly, the lines produced by the laser beam were electrically conductive; we measured the electrical resistance of the wires to be $\approx 250 \Omega \mathrm{cm}^{-1}$. This value was similar to electrical resistance measured by Lessing et al. for printed silver lines on different types of hydrophobic paper (100 and $\left.400 \Omega \mathrm{cm}^{-1}\right) \cdot{ }^{[45]}$ Due to its simplicity, we believe that our method, after further modifications and optimizations, might be used as an alternative method to the fabrication of conductive wires.

\section{Conclusion}

This paper describes a convenient and rapid method to prepare paper-templated and fabric-templated structures composed of noble metals. The composition of these paper-templated structures can be varied by changing the composition of the solutions of the precursors. The shape of the paper-templated structures can also be tailored by changing the shape of the original template. The retention of shape in going from the original paper template to metal structure is however, only approximate. Achieving better retention-with less shrinkage and warping-would be required for applications requiring specific, complex shapes.

Although this study has focused on the fabrication of structures composed mainly of noble metals, this method can also be used for the fabrication of metal oxide structures. For example, by using solutions of $\mathrm{TiCl}_{3}$ and $\mathrm{AlCl}_{3}$ as precursors, we produced paper-templated structures composed of $\mathrm{TiO}_{2}$ and $\mathrm{Al}_{2} \mathrm{O}_{3}$ (Figure $\mathrm{S} 12$, Supporting Information). The method is generally much faster than others described in the literature, as it requires only a few minutes (compared to few hours) to accomplish. ${ }^{[24]}$

Other porous structures that were made of noble metals, and exhibited high surface areas, have the potential to serve as electrodes in electrochemical sensors and biosensors, ${ }^{[46]}$ as well as in catalysis (e.g., for the oxidation of organic molecules (such as methanol, formic acid), ${ }^{[47]}$ and for oxygen reduction reactions used in fuel cells ${ }^{[48]}$ ). The paper-templated structures we prepared are fibrous, conductive, and are gas and liquid permeable. They also possess more than 20 times higher surface area than their projected area. The paper-templated structures thus have properties that make them potentially useful in catalysis, sensing, and electroanalysis.

\section{Supporting Information}

Supporting Information is available from the Wiley Online Library or from the author.

\section{Acknowledgements}

The authors wish to acknowledge the Defense Threat Reduction Agency (Award No. HDTRA1-14-C-0037) for salary support to D.C.C., the Department of Energy Award No. DE-SC00000989 for salary support to F.C.S., the Army Research Office Award No. N00014-10-1-0942 for salary support to A.T., the National Science Foundation (Award No. DMR-0820484) for salary support to S.T., and the University of Oviedo (Campus de Excelencia Internacional) and the Spanish Ministry of Economy and Competitiveness (Project No. MICINN CTQ2011-25814) for support to M.T.F.-A. The authors also want to thank Dr. Alar Ainla for taking the photos of the structures, Dr. H. Greg Lin for performing the XPS experiments, and Dr. Baris Unal for useful discussions.

Received: October 6, 2016 Revised: December 7, 2016 Published online:

[1] C. M. Welch, R. G. Compton, Anal. Bioanal. Chem. 2006, 384, 601.

[2] A. J. Arvia, R. C. Salvarezza, W. E. Triaca, J. New Mater. Electrochem. Syst. 2004, 7, 133.

[3] R. Garcia-Gonzalez, M. T. Fernandez-Abedul, A. Pernıa, A. Costa-Garcia, Electrochim. Acta 2008, 53, 3242. 
[4] S. Kishioka, J. Nishino, H. Sakaguchi, Anal. Chem. 2007, 79, 6851.

[5] O. D. Velev, P. M. Tessier, A. M. Lenhoff, E. W. Kaler, Nature 1999, 401, 548.

[6] O. D. Velev, E. W. Kaler, Adv. Mater. 2000, 12, 531.

[7] P. Jiang, J. Cizeron, J. F. Bertone, V. L. Colvin, J. Am. Chem. Soc. 1999, 121, 7957

[8] K. M. Kulinowski, P. Jiang, H. Vaswani, V. L. Colvin, Adv. Mater. $2000,12,833$.

[9] J. E. G. J. Wijnhoven, S. J. M. Zevenhuizen, M. A. Hendriks, D. Vanmaekelbergh, J. J. Kelly, W. L. Vos, Adv. Mater. 2000, 12, 888.

[10] H. Xu, W. A. Goedel, Small 2005, 1, 808.

[11] H. Y. Son, J. H. Ryu, H. Lee, Y. S. Nam, ACS Appl. Mater. Interfaces 2013, 5, 6381.

[12] S. Sakai, S. Kawa, K. Sawada, M. Taya, Gold Bull. 2013, 46, 97.

[13] Y. Sun, B. T. Mayers, Y. Xia, Nano Lett. 2002, 2, 481

[14] Y. Sun, B. T. Mayers, Y. Xia, Adv. Mater. 2003, 15, 641.

[15] J. Erlebacher, M. J. Aziz, A. Karma, N. Dimitrov, K. Sieradzki, Nature 2001, 410, 450.

[16] R. Li, K. Sieradzki, Phys. Rev. Lett. 1992, 68, 1168.

[17] Y. Ding, J. Erlebacher, J. Am. Chem. Soc. 2003, 125, 7772.

[18] Y. Ding, Y.-J. Kim, J. Erlebacher, Adv. Mater. 2004, 16, 1897.

[19] J. G. Giuliani, T. E. Benavidez, G. M. Duran, E. Vinogradova, A. Rios, C. D. Garcia, J. Electroanal. Chem. 2016, 765, 8.

[20] R. Yuan, X. Fu, X. Wang, P. Liu, L. Wu, Y. Xu, X. Wang, Z. Wang, Chem. Mater. 2006, 18, 4700.

[21] Y. Sun, X. Hu, J. C. Yu, Q. Li, W. Luo, L. Yuan, W. Zhang, Y. Huang, Energy Environ. Sci. 2011, 4, 2870.

[22] L. Zhou, J. He, J. Zhang, Z. He, Y. Hu, C. Zhang, H. He, J. Phys. Chem. C 2011, 115, 16873.

[23] B. Zhao, Z. Shao, J. Phys. Chem. C 2012, 116, 17440.

[24] J. Huang, T. Kunitake, J. Am. Chem. Soc. 2003, 125, 11834.

[25] J. He, T. Kunitake, T. Watanabe, Chem. Commun. 2005, 6, 795.

[26] W. Lan, E. J. Maxwell, C. Parolo, D. K. Bwambok, A. B. Subramaniam, G. M. Whitesides, Lab Chip 2013, 13, 4103.

[27] K. Hu, D. Lan, X. Li, S. Zhang, Anal. Chem. 2008, 80, 9124.
[28] Y. H. Tan, J. A. Davis, K. Fujikawa, N. V. Ganesh, A. V. Demchenko, K. J. Stine, J. Mater. Chem. 2012, 22, 6733.

[29] O. N. Shornikova, E. V. Kogan, N. E. Sorokina, V. V. Avdeev, Russ. J. Phys. Chem. A 2009, 83, 1022.

[30] W.-C. Li, A.-H. Lu, W. Schmidt, F. Schuth, Chem. Eur. J. 2005, 11, 1658.

[31] R. M. Rioux, H. Song, J. D. Hoefelmeyer, P. Yang, G. A. Somorjai, J. Phys. Chem. B 2005, 109, 2192.

[32] J. C. Chaston, Platinum Metals Rev. 1975, 19, 135.

[33] J. Havel, E. M. Peña-Méndez, F. Amato, N. R. Panyala, V. Buršíková, Rapid Commun. Mass Spectrom. 2014, 28, 297.

[34] G. T. Meaden, Electrical Resistance of Metals, Springer LLC, New York 1965, p. 4

[35] J. A. Greenwood, Br. J. Appl. Phys. 1966, 17, 1621.

[36] A. Nemiroski, D. C. Christodouleas, J. W. Hennek, A. A. Kumar, E. J. Maxwell, M. T. Fernández-Abedul, G. M. Whitesides, Proc. Natl. Acad. Sci. USA 2014, 111, 11984.

[37] A. J. Bard, L. R. Faulkner, Electrochemical Methods: Fundamentals and Applications, Wiley-VCH, Weinheim, Germany 2000.

[38] I. Streeter, G. G. Wildgoose, L. Shao, R. G. Compton, Sens. Actuators, $B$ 2008, 133, 462.

[39] D. K. Shen, S. Gu, Bioresour. Technol. 2009, 100, 6496.

[40] C. F. Cullis, M. M. Hirschler, R. P. Townsend, V. Visanuvimol, Combust. Flame 1983, 49, 249.

[41] K. Li, R. Khanna, J. Zhang, Z. Liu, V. Sahajwalla, T. Yang, D. Kong, Fuel 2014, 133, 194.

[42] T. Reed, Free Energy of Formation of Binary Compounds, MIT Press, Cambridge, MA 1971.

[43] K. Otto, I. Oja Acik, M. Krunks, K. Tõnsuaadu, A. Mere, J. Therm. Anal. Calorim. 2014, 118, 1065.

[44] A. E Newkirk, D. W. McKee, J. Catal. 1968, 11, 370.

[45] J. Lessing, A. C. Glavan, S. B. Walker, C. Keplinger, J. A. Lewis, G. M. Whitesides. Adv. Mater. 2014, 26, 4677.

[46] A. Walcarius, A. Kuhn, Trend Anal. Chem. 2008, 27, 593.

[47] J. Zhang, C. M. Li, Chem. Soc. Rev. 2012, 41, 7016.

[48] Y. Qiao, C. M. Li, J. Mater. Chem. 2011, 21, 4027. 